\title{
Utilization of $f$-Chart Method for Designing Solar Thermal Heating System
}

\author{
Dasari Deepika $^{1,}$ M. Ahmed Ali Baig ${ }^{2,}$ A. Raji Reddy ${ }^{3}$ D. Maneaih ${ }^{4}$ \\ ${ }^{I}$ PG Scholar, Mechanical Department, CMRTC, JNTU, Hyderabad, Telangana, India \\ ${ }^{2,3}$ Professor, Mechanical Department, CMRTC, JNTU, Hyderabad, Telangana, India \\ ${ }^{4}$ Associate professor, Mechanical Department, CMRTC, JNTU, Hyderabad, Telangana, India
}

\begin{abstract}
Solar energy systems convert solar energy into useful energy. Design of solar systems is complicated because of the presence of both predictable and unpredictable parameters. Predictable parameters include performance characteristics of collectors and other components whereas unpredictable parameters include weather data such as solar radiation, ambient temperature which exhibits nonlinear behavior. This nonlinear dependence makes it difficult to analyze the performance by simply observing their response to short-term or average weather conditions. Thus this work analyzes the use of $f$-chart method in designing liquid solar heating systems due to its simplicity and ability to estimate the fraction of total heating load supplied by solar heating system. This method is widely used in designing both active and passive solar heating systems, especially in selecting the sizes and type of solar collectors that provide the hot water and heating loads. This paper includes estimation of percentage of load contributed with a fixed collector area of 1 $m^{2}$ for a solar water heating system in Hyderabad.
\end{abstract}

Keywords: F-chart method, Solar Energy, Total heating load, Water Heater, percentage of load contributed.

\section{Introduction}

Solar energy is simply a radiant energy direct from the sun to earth surface. But only a fraction of this energy gets to the Earth surface. Some of them are reflected back into the space, while others are scattered by water droplets in the clouds and dust particles.

Solar energy is used for a variety of heating purposes such as heating of home and spaces, industrial processes, thermal treatment of water supply, production of hot water and steam for industries etc. It is also used in the generation of electricity using solar-powered thermal electric generating systems. Solar energy systems convert solar energy into either thermal or electrical energy and such systems can either be passive or active systems. The passive systems do not require input of any form of energy apart from the solar radiation, while the active systems require additional mechanisms such as circulation pumps, air blowers or automatic systems.

Proper design of solar water heating system is important to assure maximum benefit to the user, especially for a large system. Designing a solar hot water system involves appropriate sizing of different components based on predicted solar isolation and hot water demand. A number of design methods are available for solar water heating systems.

\section{Design methods for solar thermal processes can be put in three general categories:}

The first category applies to system in which collector operating temperature is known or can be estimated and for which critical radiation levels can be find out.

Eg: Utilizability method, are based on analysis of hourly weather data to obtain the fraction of the total month's radiation that is above critical level.

The second category includes those that are correlations of the result of a large number of detailed simulations. Eg: f-chart method.

The third category involves Short cut simulation in which simulations are done using meteorological data for representative days.

Eg: SOLCOST method

\section{F-Chart Method}

The F-chart method is developed by Klien et al. (1976, 1977) and Beckman et al. (1977). The results of many numerical experiments are correlated in terms of easily calculated dimensionless variables.

F-chart method is used for estimating the annual thermal performance of active heating systems for buildings (using either liquid or air as working fluid) where the minimum temperature of energy delivery is near $20 \mathrm{C}$. 
This method provides a means for estimating the fraction of total heating load that will be supplied by solar energy for a given solar heating system.

The primary design variable is collector area; secondary variables are collector type, storage capacity fluid flow rates, and collector heat exchanger sizes. The method is a correlation of the results of many hundreds of thermal performance simulations of solar heating systems. The conditions of the simulations were varied over appropriate ranges of parameters for practical system designs. The resulting correlations give $f$, the fraction of monthly heating loads (for space heating and hot water) supplied by solar energy as a function of two dimensionless parameters. One is related the ratio of collector losses to heating loads and the other is related to the ratio of absorbed solar radiation to heating loads.

The two dimensionless groups are

$$
\begin{aligned}
& \mathrm{X}=\frac{\text { (Collector energy loss during a month ) }}{(\text { Total heating load during a month ) }}(1) \\
& \mathrm{X}=\mathrm{F}_{\mathrm{R}} \mathrm{U}_{\mathrm{L}} \frac{\mathrm{F}_{\mathrm{R}}^{\prime}}{\mathrm{F}_{\mathrm{R}}}\left(\mathrm{T}_{\text {ref }}-\overline{\mathrm{T}}_{\mathrm{a}}\right) \Delta \mathrm{t} \frac{\mathrm{A}_{\mathrm{c}}}{\mathrm{L}}(2) \\
& \mathrm{Y}=\frac{\text { (Total energy absorbed on the collector plate during a month ) }}{(3)} \\
& \mathrm{Y}=\mathrm{F}_{\mathrm{R}}(\tau \alpha)_{n} \frac{\mathrm{F}_{\mathrm{R}}^{\prime}}{\mathrm{F}_{\mathrm{R}}}\left[\frac{(\tau \bar{\alpha})}{(\tau \alpha)_{n}}\right] \overline{\mathrm{H}_{\mathrm{T}}} \mathrm{N} \frac{\mathrm{A}_{\mathrm{C}}}{\mathrm{L}}(4)
\end{aligned}
$$$$
\mathrm{f}=1.029 \mathrm{Y}-0.065 \mathrm{X}-0.245 \mathrm{Y}^{2}+0.0018 \mathrm{X}^{2}+0.0215 \mathrm{Y}^{3}(5)
$$

Subject to conditions $0<=\mathrm{X}<=15 ; 0<=\mathrm{Y}<=3$.

Where,

$\mathrm{A}_{\mathrm{C}}=$ Area of solar collector $\left(\mathrm{m}^{2}\right)$

$\mathrm{F}_{\mathrm{R}}=$ Collector-heat exchanger efficiency factor $(\%)$

$\mathrm{F}^{\mathrm{R}}=$ Collector heat removal factor $(\%)$

$\mathrm{U}_{\mathrm{L}}=$ Collector overall energy loss coefficient $\left(\mathrm{W} / \mathrm{m}^{2}-{ }^{\circ} \mathrm{C}\right)$

$\Delta \mathrm{t}=$ Total number of seconds or hours in the month

$\overline{\mathrm{T}_{\mathrm{a}}}=$ Monthly average ambient temperature $\left({ }^{\circ} \mathrm{C}\right)$

$\mathrm{L}=$ Monthly total heating load (GJ)

$\overline{\mathrm{H}_{\mathrm{T}}}=$ Monthly averaged daily radiation incident on collector surface per unit area $\left(\mathrm{MJ} / \mathrm{m}^{2}\right)$

$\mathrm{N}=$ Number of days in the month

$(\tau \alpha)=$ Monthly average Transmittance-absorptance product $(\%)$

$(\overline{\tau \alpha})=$ Normal transmittance-absorptance product $(\%)$

$\mathrm{T}_{\text {ref }}=$ Reference temperature $\left(100^{\circ} \mathrm{C}\right)$

In F-chart method, system performance is expressed in terms of $\mathrm{f}$, which is the fraction of the heating load supplied by solar energy during each month. The relationship between $\mathrm{f}$ and the dimensionless variable $\mathrm{X}$ and $\mathrm{Y}$ is shown in figure 1 for the water system. The f-chart method proceeds as follows: (i) the dimensionless variables $\mathrm{X}$ and $\mathrm{Y}$ are calculated for each calendar month. (ii) The intersection of the $\mathrm{X}$ and $\mathrm{Y}$ values in figure 1 locates a value of $f$ which is the fraction of the heating load supplied by solar energy for that month. The calculations are repeated for each month. The fraction of the annual heating load supplied by solar energy $f$ is the sum of the product of monthly solar energy fraction $\mathrm{f}_{\mathrm{i}}$ and the monthly thermal load $\mathrm{L}_{\mathrm{i}}$ divided by the annual load L.

$$
f=\frac{\Sigma f_{i} L_{i}}{\Sigma L_{i}}
$$

\section{System Description}

The f-charts have been developed for the standard system configurations, liquid and air system for space (and hot water) heating and systems for service hot water only. A schematic diagram of the standard heating system using liquid heat transfer fluids is shown in fig .2. The sytem normally uses an antifreeze solution in collector loop and water as storage medium. Collectors may be drained when energy is not being collected, in which case water is used directly in the collectors and collector heat exchanger is not needed. A water-to-air load heat exchanger is used to transfer heat from the storage tank to a domestic hot water subsystem. 
The standard configuration of a solar air heating system with a pebble bed storage unit is shown in fig.3. Other equivalent arrangements of fans and dampers can be used to provide the same modes of operation. Energy required for domestic hot water is provided by an air-to-water heat exchanger in the hot air duct leaving the collector. During summer operation, it is best not to store solar energy in the pebble bed, and a manually operated storage bypass is usually provided in this system to allow summer water heating. The ranges of design parameters used in developing the correlations for this system are shown in table1.

The standard configuration for a solar domestic water heating system is shown in fig.4. The collector may heat either air or liquid. The solar energy is transferred via a heat exchanger to a domestic hot water (DHW) preheat tank, which supplies solar heated water to conventional water heater or an in-line low capacitance "zip" heater where the water is further heated to the desired temperature if necessary. A tempering valve may be provided to maintain the tap water below a maximum temperature. These changes in the system configuration don not have major effects on the performance of the system. Detailed simulations of these systems have been used to develop correlations between dimensionless variables and $\mathrm{f}$, the monthly fraction of loads carried by solar energy.

\section{Storage Capacity}

The Annual system performance is relatively intensive to storage capacity as long as capacity is more than approximately 50 liters of water per square meter of collector. When the costs of storage are considered, there are broad optima in the range of 50 to 200 liters of water per square meter of collector.

The f-chart was developed for storage capacity of 75 liters of stored water per square meter of collector area. The performance of systems with storage capacities in the range of 37.5 to $3001 / \mathrm{m}^{2}$ can be determined by multiplying the dimensionless group $\mathrm{X}$ by a storage size correction factor $\mathrm{X}_{\mathrm{c}} / \mathrm{X}$.

$\frac{X_{c}}{X}=\left(\frac{\text { Actual storage capacity }}{\text { standard storage capacity }}\right)^{-0.25}$ (7)

For $0.5 \leq\left(\frac{\text { Actual storage capacity }}{\text { standard storage capacity }}\right) \leq 4.0$

Where, the standard storage capacity is 75 liters of water per square meter of collector area.

\section{Design objective}

A solar water heating system with fixed collector area of $1 \mathrm{~m}^{2}$ is considered for this particular study for Hyderabad location with various load conditions. Water heating collector characteristics for the available collectors are: $\mathrm{F}_{\mathrm{R}} \mathrm{U}_{\mathrm{L}}=5.22 \mathrm{~W} / \mathrm{m} 2, \mathrm{~F}_{\mathrm{R}}(\tau \alpha)_{\mathrm{n}}=0.567$ and $(\tau \alpha) /(\tau \alpha)_{\mathrm{n}}=0.63$ as determined from standard collector tests. Assume the collector-heat exchanger correction factor, $\mathrm{F}_{\mathrm{R}} / \mathrm{F}_{\mathrm{R}}$ is 1 .

\begin{tabular}{|ll|}
\hline $0.6 \leq(\tau \alpha)_{\mathrm{n}} \leq 0.9$ \\
\hline $5 \leq \mathrm{F}_{\mathrm{R}} \cdot \mathrm{A} \quad \leq 120 \mathrm{~m}^{2}$ \\
\hline $2.1 \leq \mathrm{U}_{\mathrm{L}} \leq 8.3 \mathrm{~W} / \mathrm{m}^{2}{ }^{\circ} \mathrm{C}$ \\
\hline $30 \leq \beta \quad \leq 80 \mathrm{deg}$ \\
\hline $83 \quad \leq(\mathrm{U} . \mathrm{A})_{\mathrm{h}} \leq 667 \mathrm{~W} /{ }^{\circ} \mathrm{C}$ \\
\hline
\end{tabular}

\section{Results And Discussions}

The aim of the work to find the contribution of an installed solar water heater with $1 \mathrm{~m} 2$ area is discussed with the help of figures indicated below. Fig1 depicts the scenario where the load is considered to 100 liters, which can be sufficient for an average family of 3 or 4 people. The variation in temperature of the 100 liter water at four different ranges is shown. It can be seen that, $1 \mathrm{~m}^{2}$ solar water heater can fulfill the complete load at $40^{\circ} \mathrm{C}$. As the requirement increases the contribution of solar water heater decreases. The figures depicted however do not consider the losses occurring at user end. Fig 2 presents the results of increased load of 200 liters, which can be sufficient for an average family of 6 or 7 people. It can be seen that 1 $\mathrm{m} 2$ area SWH cannot fulfill the complete load requirement of 200 liters at any set of temperature presented in the study. It can contribute a maximum of $74.92 \%$ only. 


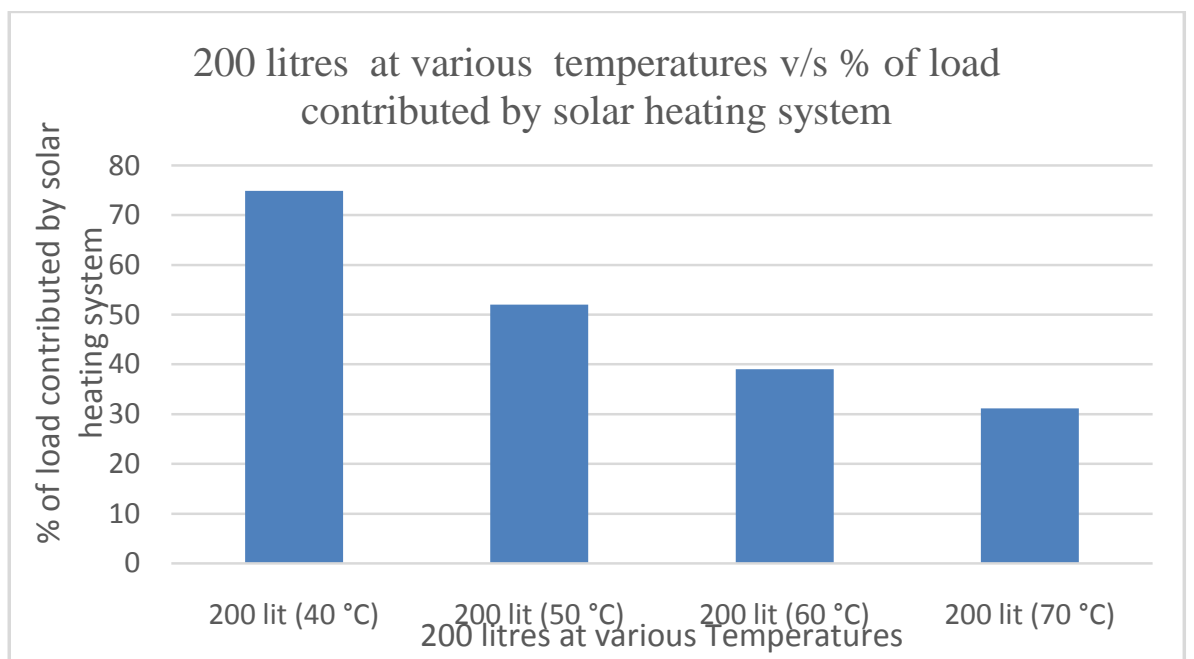

Fig 1 Contribution of SWH vs Load (100 Liters)

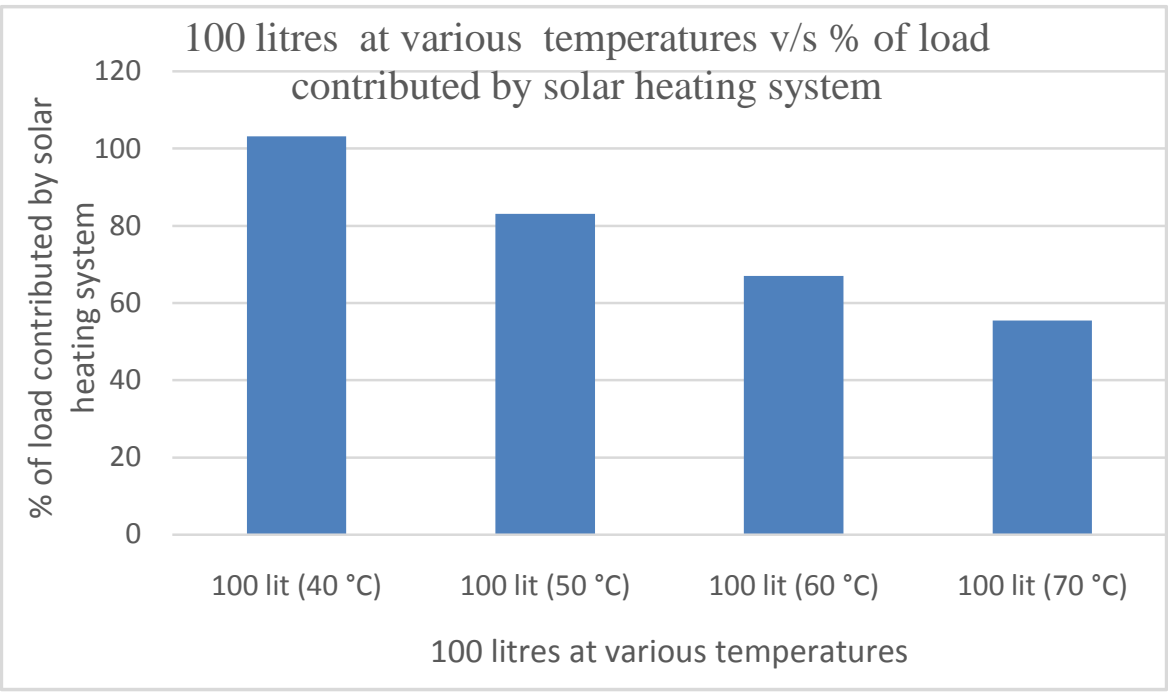

Fig 2 Contribution of SWH vs Load (200 Liters)

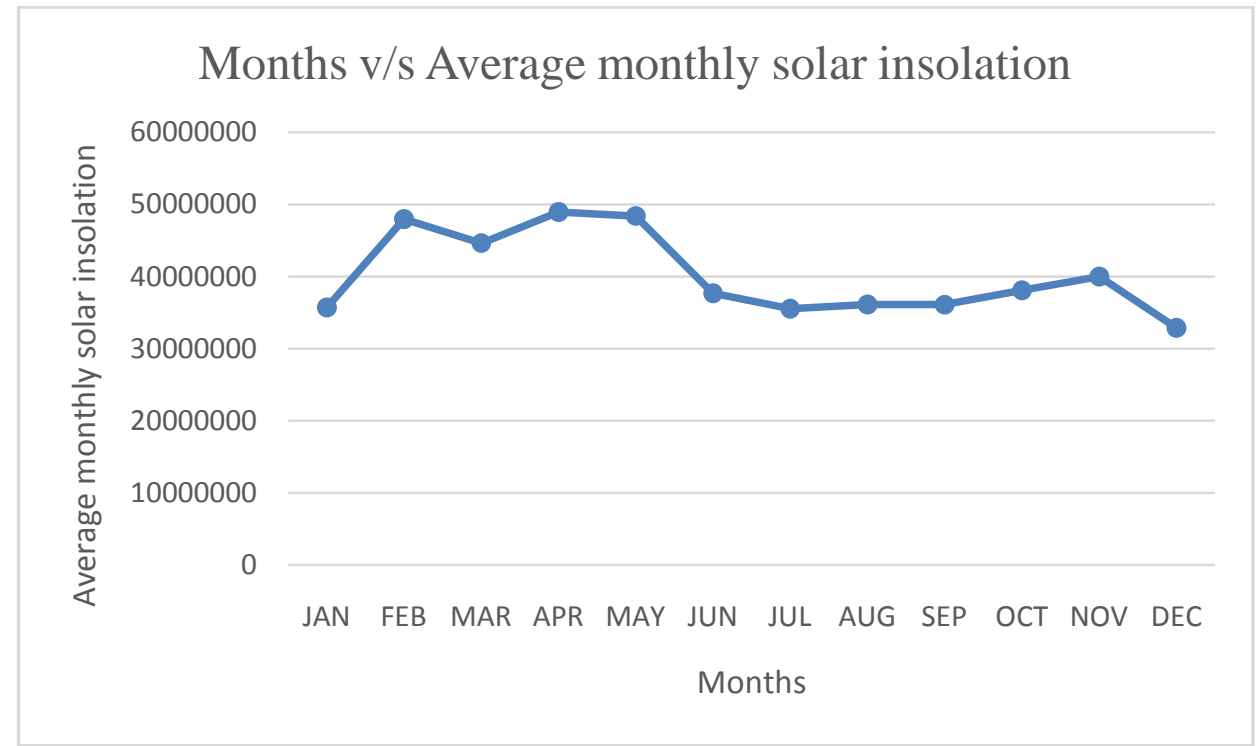

Fig 3 Average Monthly Solar Insolation vs Months 


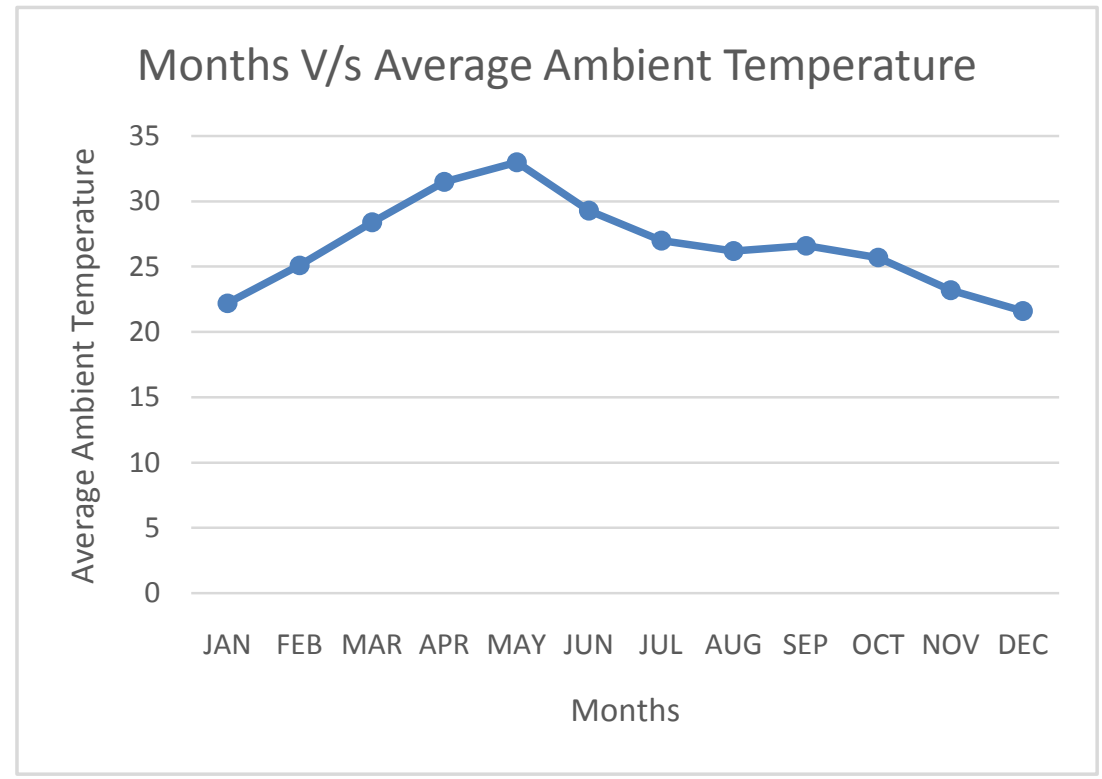

Fig 4 Average Ambient Temperature $\left({ }^{\circ} \mathrm{C}\right)$ vs Months

Figure 4 and Figure 5 graphically shows the average solar insolation and average ambient air temperature for different months for the city of Hyderabad respectively. It is obvious from the plot that Hyderabad receives maximum soalr insolation for the month of April, i.e. $4.896 \mathrm{MJ} / \mathrm{m}^{2}$ and maximum ambient air temperature in the month of May.

This analysis results that the percentage of load contributed is maximum with lower load and lowest temperature. As the temperature increases the percentage of load contributed by solar heating system decreases.

\section{Conclusion}

The f-chart method provides a means of quickly estimating the long-term performance of solar heating systems of the standard configurations. The data needed are monthly average radiation and temperature, the collector parameters available from standard collector tests and estimates load.

This work has adopted f-chart method in designing liquid solar heating systems due to its simplicity and ability to estimate the fraction of total heating load supplied by solar heating system with fixed collector area of $1 \mathrm{~m}^{2}$ with various loads and various temperatures. The results indicate that the percentage of load contributed is maximum with lower load and lowest temperature. As the temperature increases the percentage of load contributed by solar heating system decreases, i.e. in Hyderabad a $1 \mathrm{~m}^{2}$ area SWH can contribute $100 \%$ load of 100 liters/day at $40{ }^{\circ} \mathrm{C}$. However the type of collector selection and maintenance also plays an important role.

The major advantage method is that it provides a means of designing solar energy systems with less computational effort. Performance estimates obtained from the f-chart method have been shown to be in good agreement with the experimental performance of many carefully monitored systems, but cannot be used where there are many factors (such as improper installation) that prevent a system operating as designed.

\section{References}

[1]. J.A Duffie, and W.A Beckman, Solar Engineering of Thermal Processes, Wiley Interscience,Newyork,1980

[2]. S. A. Klein, W. A. Beckman and J. A. Duffie, “A Design Procedure For Solar Heating Systems”, Solar energy 18, 113- 126,(1976)

[3]. M. Ahmed Ali Baig and Amit Kamble, "Concept of Solar towers in India", National level Conference for PG and PhD Scholars held at NMAM Institute of Technology, Nitte, Karnataka on 28 \& 29 April 2006.

[4]. M. Ahmed Ali Baig and Anand Shivpuji, "On the Analysis of Solar Collector Performance Using the HottelWhiller-Bliss Equation - A Series and Mass Flow Optimization Model". Paper presented in national level conference, held at Hosur, TamilNadu on March 2008.

[5]. A. Athienitis, S.A Kalogir, "Modelling and simulation of solar thermal systems",comprehensive renewable energy,volume 3,2012

[6]. Ministry of new and renewable energy http://mnre.gov.in/information/manufacturesindustriesarchite ctsconsultingorganisation

[7]. F-chart manual,F-chart software, The university of Wisconsin, Madison 
[8]. M. Ahmed Ali Baig, Md. Rafeeq, Asif Afzal and S.A. Khan "Performance Analysis of Different Types of Solar Waters Heaters under Varying Load Demands", National Conference on Emerging Technologies in Renewable Energy, held at Guru Nanak Dev Engineering College, Bidar during 12-13th April, 2012.

[9]. K.Sujith, "Design of Active Solar Water Heating System Using F-Chart Method", Energy Engineering and Management, Department of mechanical engineering National Institute of Technology, Calicut, Kerala, india673601 